\title{
Investigation of Reliability and Complexity of Torque Control for Switched Reluctance Drives
}

\author{
N. K. Dankadai, M. A. Elgendy, S. P. McDonald, D. J. Atkinson, G. Atkinson \\ School of Engineering \\ Newcastle University \\ Newcastle Upon Tyne, UK \\ n.k.dankadai2@newcastle.ac.uk \\ mohammed.elgendy@newcastle.ac.uk
}

\begin{abstract}
Reliability is of great concern in applications like automotive, aerospace and home appliances in which Switched Reluctance Motor (SRM) is getting more popularity. Therefore, the reliability of the motor drive hardware and control algorithm should be ensured. In this study, the reliability and complexity of several widely used control methods for SRM drive are described using theoretical and simulation analysis. The effect of common errors associated with a practical SRM drive on its control systems' reliability is analyzed. In addition, an investigation on the relationship between system complexity and reliability of SRM control based on information flow complexity within the control technique is also presented. Three methods including Current Chopping Control (CCC), Torque Sharing Function based Direct Instantaneous Torque Control (TSF-DITC) and Direct Torque Control (DTC) are considered and compared. The results obtained showed that the $\mathrm{CCC}$ method shows the highest robustness to measurement error followed by the TSF-DITC then the DTC. However, the TSF-DITC method achieved superior torque characteristics while maintaining high robustness and reliability.
\end{abstract}

Keywords - Complexity analysis, error analysis, switched reluctance motor drives, torque control

\section{INTRODUCTION}

Switched reluctance motor based electric drives have been used in home appliances, automotive, aerospace and industrial applications because of its high reliability, low cost and wide speed range [1]-[5]. However, its disadvantage of high torque ripple limits its application. Many torque ripple reduction methods have been proposed like Direct Torque Control (DTC), Direct Instantaneous Torque Control (DITC) and Torque Sharing Function (TSF). In DTC method, the machine's instantaneous torque and flux are the control variables. The desired torque output is generated from selecting a stator voltage space vector according to calculated errors of the resultant instantaneous torque and stator flux. DITC method is a simplified form of DTC method in which only the instantaneous phase torque is directly regulated with no consideration of the stator flux. A comparison of DITC and
DTC is presented in [6]. Linear, cubic and exponential TSF are also commonly employed to reduce the torque ripple in SRM drives. This method distributes the desired resultant torque among the phase torque of the SRM first before the torque control. In [7], an online compensation of torque sharing function is added to the DITC method to ensure that the incoming and the outgoing phases are appropriately distributed and regulated to improve the torque ripple reduction. The pros and cons of the aforementioned commonly used methods to control SRMs are depicted in Table I. By considering the functional structures of a three-phase CCC, a three-phase DTC and a three-phase TSF-DITC of an SRM shown in Fig. 1. A conventional $\mathrm{CCC}$ has two sub-functions (modules) that maintain the resultant current at a specified reference with no consideration of the motor's torque [8]. A conventional DTC consists of seven sub-functions to ensure good torque characteristics over a wide range of operation while in TSFDITC, the functional modules in DTC are reduced to four without compromising performance in torque ripple reduction.

Generally, SRM drives should ensure a good torque characteristic with high reliability. Despite several control methods have been developed for switched reluctance machine over the last decade, especially for applications that require a high level of reliability and robustness, how to evaluate the reliability and robustness of the control methods still remains largely undetermined. By considering the reliability of electric drive's control, feedback measurement error is one of the main factors that may result in a fault that leads to failure of the system. A fault, in this case, can be defined as a defect with an open loop or closed loop control of the electric drive that causes its failure. Hence, the failure can be defined as the inability of the drive's control system or any of its component to perform a required function according to its specification. The objective of this study is to investigate the effect of errors and structural complexity on reliability and robustness of torque control techniques for switched reluctance motor control

TABLE I. COMPARISON OF SRM CONTROL

\begin{tabular}{|l|l|l|l|}
\hline Technique & Methodology & Advantage & Disadvantage \\
\hline CCC & $\begin{array}{l}\text { The current is controlled by using a } \\
\text { hysteresis current controller. }\end{array}$ & $\begin{array}{l}\text { - Simple control structure } \\
\text { Robustness to measurement } \\
\text { errors. }\end{array}$ & $\begin{array}{l}\bullet \text { High torque ripple } \\
\text { P Poor closed loop dynamics }\end{array}$ \\
\hline DTC & $\begin{array}{l}\text { The desired torque is obtained by } \\
\text { using torque and flux estimation with } \\
\text { hysteresis controller. }\end{array}$ & $\begin{array}{l}\bullet \text { Low torque ripple } \\
\text { Good performance over a } \\
\text { wide range of speed. }\end{array}$ & $\begin{array}{l}\text { Prior-knowledge of machine characteristics is } \\
\text { required } \\
\text { Requires multiple control calculations. } \\
\text { - Requires high switching frequency }\end{array}$ \\
\hline TSF-DITC & $\begin{array}{l}\text { A linear or non-linear torque sharing } \\
\text { function (online or offline) is designed } \\
\text { and used to obtain a desired resultant } \\
\text { torque. }\end{array}$ & $\begin{array}{l}\text { - Low torque ripple } \\
\text { Accurate reference torque } \\
\text { tracking. }\end{array}$ & $\begin{array}{l}\text { - Offline design of torque profile is required. } \\
\text { Prior-knowledge of machine characteristics is } \\
\text { required } \\
\text { Requires high switching frequency }\end{array}$ \\
\hline
\end{tabular}




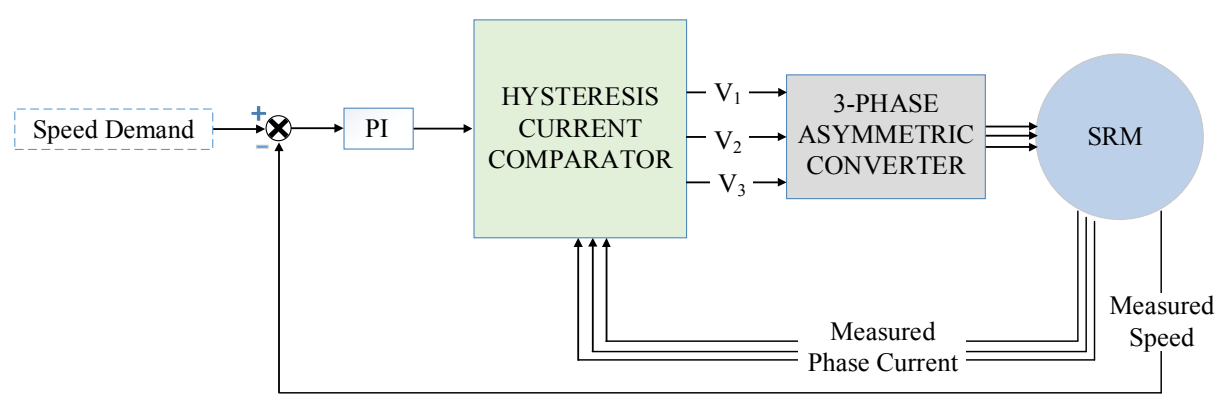

(a) $\mathrm{CCC}$

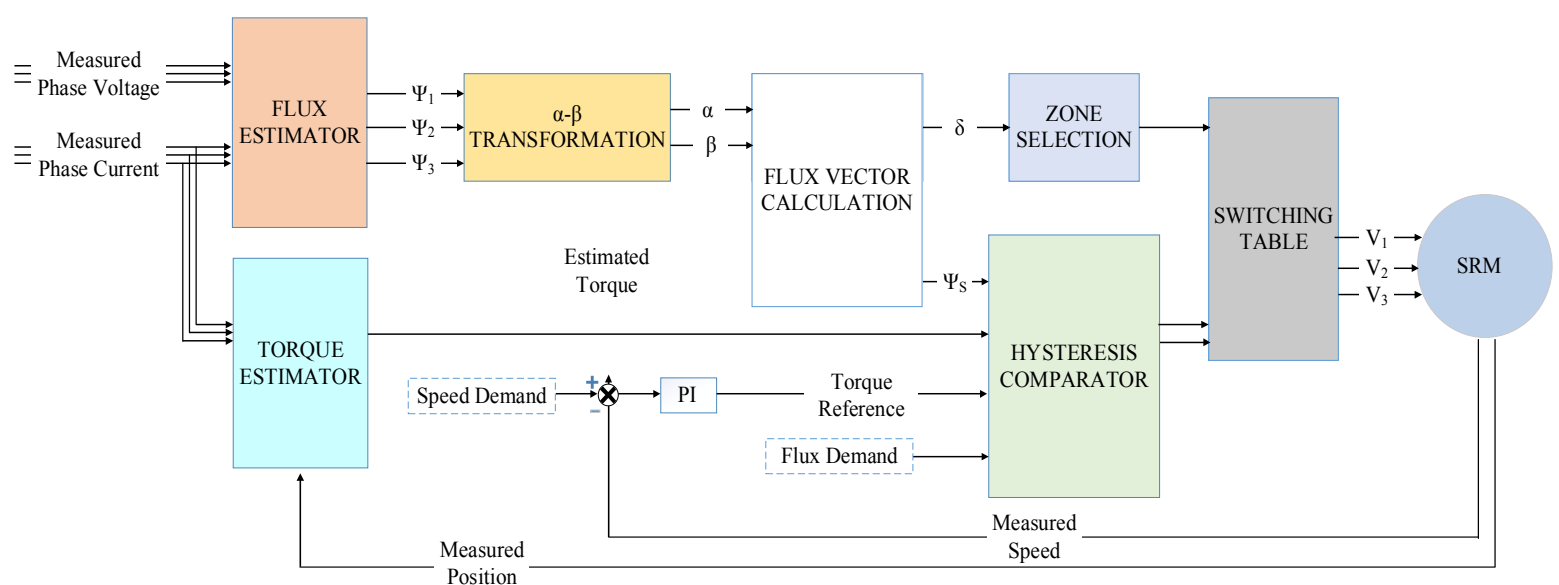

(b) DTC

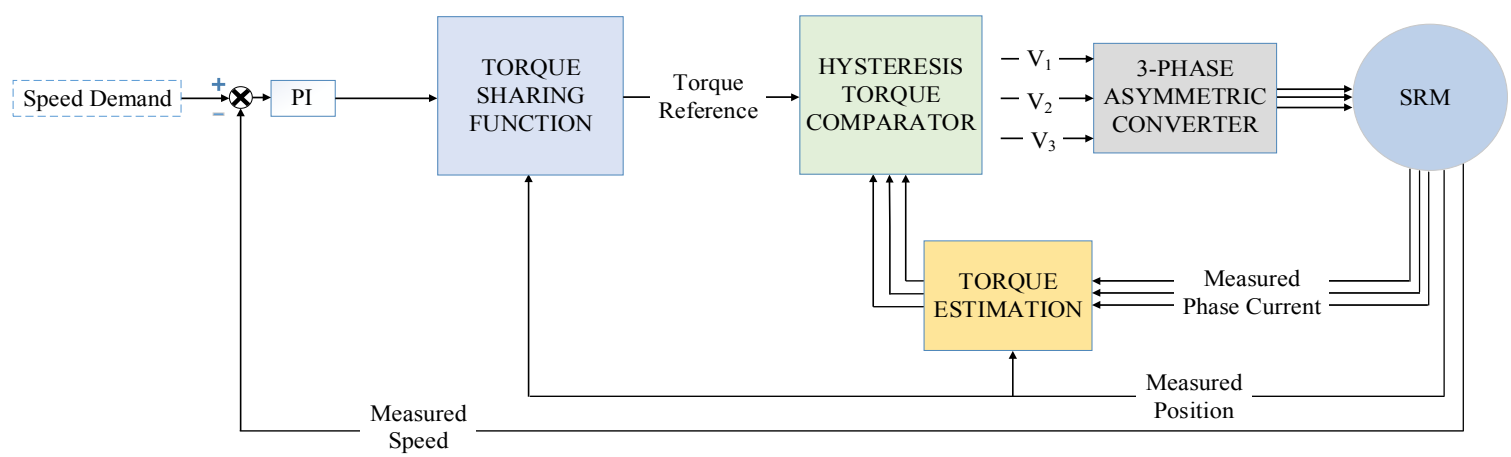

(c) TSF-DITC

Fig. 1. Control methods of SRM

\section{RELIABILITY ANALYSIS OF SRM CONTROL}

Having a standard method of quantifying the reliability of control systems have been an unresolved issue for decades because their failures are time and environment dependent. Nevertheless, factors that can be propositional or inversely proportional to the reliability of control algorithms have been presented by researchers. These factors include Robustness, Mean Time Between Failure, Flexibility, Error Tolerance, Fault Tolerance, Device Dependence, Accuracy, Recoverability, Usability, and Simplicity [9-12]. Control algorithm failures occur if its behaviour differs from the specified one because of errors in the system.

Generally, systems that are error-prone have a high probability of failure and furthermore, systems that are error- prone and complex will have a significantly higher probability of failure, thus making the overall system highly unreliable. In this study, the effect of robustness and complexity on the reliability of SRM control is investigated. It can be decided from this section that complexity and measurement error have a significant negative effect on the reliability of SRM torque control, and therefore, the development of reliable torque control algorithms is necessary

\section{A. Error and Noise in SRM Control.}

The errors in the control algorithm are key factors that increase its failure rate and make it unreliable. Error components can be introduced into the control algorithm from different factors and the number and magnitude of these error components are proportional to the failure rate of the system 
[13]. Most errors in the control of SRM are often as a result of measurement error, measurement noise and parameter variation within the drive system. These errors affect the torque and flux estimations required in high-performance SRM control. An instantaneous expression showing the common error components in current measurement, voltage measurement, rotor position measurement, flux-linkage estimation and torque estimation are given in Equations 1-5, respectively.

$$
\begin{aligned}
& E_{i}(n)=E_{i O}(k)+E_{i S}(k)+E_{i N}(k) \\
& E_{v}(k)=E_{v O}(k)+E_{v S}(k)+E_{v N}(k) \\
& E_{\theta}(k)=E_{\omega}(k)=E_{T Q}(k)+E_{A Q} \\
& E_{\psi}(k)=E_{i}(k)+E_{v}(k)+E_{T Q}(k)+E_{A Q}+E_{R}(k)
\end{aligned}
$$

where $E_{i}, E_{v}, E_{\theta}, E_{\omega}$, and $E_{\psi}$, are the total measurement error in current, voltage, rotor position, and angular speed, and the total flux-linkage error, respectively. $E_{i o}$ and $E_{v o}$ are the current and voltage offset error. $E_{i S}$ and $E_{v S}$ are the current and voltage scaling error. $E_{i N}$ and $E_{v N}$ are the current and voltage signal noise error. $E_{T Q}$ and $E_{A Q}$ are the time and amplitude quantization error. $E_{R}$ is the resistance variation error.

Ideally, the instantaneous torque produced by SRM is often estimated from a lookup table $T(\theta, i)$ generated from a statictorque test. Therefore, the effect of both current and rotor position measurement should be considered when analysing the error involved in the torque estimation. Error in the measured current and rotor position will proposed corresponding error in estimated torque. Equation 5 can be used to calculate the resultant error in toque estimation at a given instance.

$E_{T}(k)=E_{\theta}(k) \frac{\partial T(\theta(k), i(k))}{\partial \theta}+E_{i}(k) \frac{\partial T(\theta(k), i(k))}{\partial i}$

where $E_{T}(k), \theta(k), i(k)$ and $T(\theta(k), i(k))$ are resultant torque estimation error, actual rotor position, actual phase current and instantaneous torque, respectively. For a given error in current and position measurement, the error in torque will be proportional to the sum of partial derivative of torque with current and partial derivative of torque with position

For the aforementioned errors, it is difficult to quantify the instantaneous error components of the current, voltage, and flux-linkage because their causal factors are system dependent and time-varying. Therefore, for analysis, an error magnitude can be assumed to represent the total error in these quantities be assumed to represent the total error in these quantities.

\section{B. Reliability of SRM Control from the Complexity Perspective}

As mentioned in Section I, the complexity of control technique is one of the key factors that affect the reliability of SRM control. Errors can be introduced into the control algorithm from different factors such as the number of modules in the system that are affected by the error components increases, the failure rate of the system also increases. Therefore, the less complicated the system, the more reliable it is [11].

An important metric of structural complexity known as Information flow metric is employed in this section to analyse the effect of system complexity of the SRM control method. Henry et al. defined structural complexity in terms of the amount of information flow (IF) between modules in software [14]. It is proven that it is a suitable and practical basis for measuring the complexity of large systems [15]-[18]. Therefore, the complexity of the SRM control system can be measured by observing the patterns of communication between the system components. Hence, an information flow complexity that considers a functional block structure as a module and the interconnection between the modules is proposed and used in this study. The expression for calculating information flow complexity is defined in (6).

$I F=\sum_{1}^{n}\left(f a n_{-} \text {in }(n) * \text { fan_out }(n)\right)^{2}$

where $n$, fan_in, and fan_out are defined as the number of modules in a system, the number of input variables passed into

\begin{tabular}{|c|c|c|c|c|}
\hline METHOD & MODULE & MODULE IF & SYSTEM IF & SOURCES OF ERROR \\
\hline \multirow[b]{2}{*}{$\mathrm{CCC}$} & SPEED CONTROL & 4 & \multirow[b]{2}{*}{148} & \multirow{2}{*}{$\begin{array}{l}E_{C C C}(k)=E_{i}(k)+E_{\omega}(k) \\
=E_{i O}(k)+E_{i S}(k)+E_{i N}(k)+E_{T Q}(k)+E_{A Q}\end{array}$} \\
\hline & $\begin{array}{l}\text { HYSTERESIS } \\
\text { COMPARATOR }\end{array}$ & 144 & & \\
\hline \multirow{4}{*}{ TSF-DITC } & SPEED CONTROL & 4 & \multirow{4}{*}{317} & \multirow{4}{*}{$\begin{array}{l}E_{T S F}(k)=E_{T}(k)+E_{\omega}(k) \\
=E_{i O}(k)+E_{i S}(k)+E_{i N}(k) \\
+2 E_{T Q}(k)+2 E_{A Q}\end{array}$} \\
\hline & TORQUE SHARING & 25 & & \\
\hline & $\begin{array}{l}\text { HYSTERESIS } \\
\text { COMPARATOR }\end{array}$ & 144 & & \\
\hline & TORQUE ESTIMATOR & 144 & & \\
\hline \multirow{8}{*}{ DTC } & SPEED CONTROL & 4 & \multirow{8}{*}{613} & \multirow{8}{*}{$\begin{array}{l}E_{D T C}(k)=E_{\psi}(k)+E_{T}(k)+E_{\omega}(k) \\
=2 E_{i O}(k)+2 E_{i S}(k)+2 E_{i N}(k) \\
+E_{v o}(k)+E_{v S}(k)+E_{v N}(k) \\
+3 E_{T Q}(k)+3 E_{A Q}\end{array}$} \\
\hline & $\begin{array}{l}\text { HYSTERESIS } \\
\text { COMPARATOR }\end{array}$ & 64 & & \\
\hline & TORQUE ESTIMATION & 144 & & \\
\hline & FLUX ESTIMATOR & 324 & & \\
\hline & $\alpha-\beta$ TRANSFORMATION & 36 & & \\
\hline & $\begin{array}{l}\text { FLUX-VECTOR } \\
\text { CALCULATION }\end{array}$ & 4 & & \\
\hline & ZONE SELECTION & 1 & & \\
\hline & SWITCHING TABLE & 36 & & \\
\hline
\end{tabular}
the module and number of output variables returned from the module, respectively.

TABLE II. COMPARISON OF SRM CONTROL 
To determine the differences in complexity between the control methods, their information flow complexity is calculated based on Fig. 1 and IF formula expressed in (6) and the results are presented in Table 2 .

The product of fan_in(n) and fan_out(n) in (6) represent the number of possible combination of the input variables to the output variables of a sub-function (module). The power of two in the equation is used to represent the non-linear relationship between the specific sub-function and other sub-functions interacting with it as it used by Belady et'al in system partitioning [19]. Lastly, the measure of the total complexity of the system is obtained by adding up all the sub-functions' 'IFs'. For example, consider the calculated IF of CCC. The speed control module has an ' $I F($ speed $)=(2 \times 1)^{2}=4$ ', the hysteresis comparator module has an ' $I F$ (hysteresis $)=(4 \times 3)^{2}$ $=144$ ' therefore, the IF complexity of CCC is ' $I F(C C C)=4$ $+144=148$ '

It can be seen that the complexity of the control methods is proportional to the number of error component involved in the system. CCC has less complexity hence less prone to error followed by TSF-DITC and finally DTC having the highest complexity and error components. This method of analysis can help to directly reduce the complexity and failure-rate of control algorithms by finding dispensable functions like in the case of reducing DTC to DITC and finding functions affected by measurement errors. Therefore, minimizing computational time and improving reliability

\section{SIMULATION RESULTS AND DISCUSSION}

To analyse the real-time effect of the measurement uncertainties on the control methods, a simulation model of the SRM drive is built in MATLAB/Simulink based on a threephase SRM and the three control algorithms. It is difficult to accurately calculate the measurement uncertainties because it is time and environment dependent. Therefore, white noise with an amplitude of $10 \%$ of the terminal measurement is generated, as shown in Fig. 2, to represent the measurement uncertainties common to an electric motor drive. This error signal is injected to the phase current feedback signals and its effect on the CCC, TSF-DITC and DTC method is shown in Fig. 3-5, respectively. The DTC requires phase voltage for flux estimation function therefore, the effect of error signals on the measured phase voltage is also shown in Fig. 6.The significant deviation in the current and voltage can be observed in these figures.

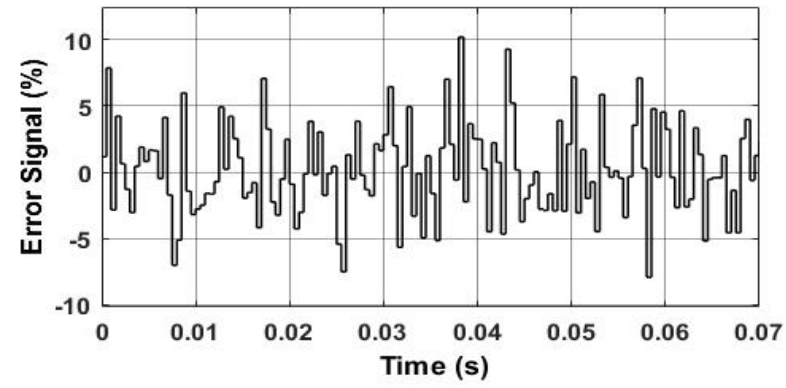

Fig. 2. $10 \%$ error signal injected to measurement terminals

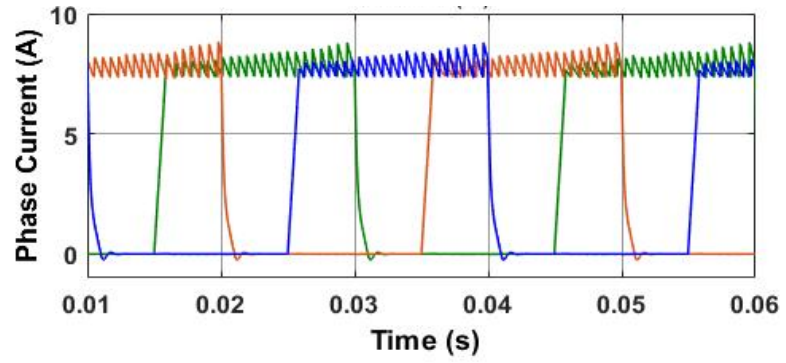

(a)

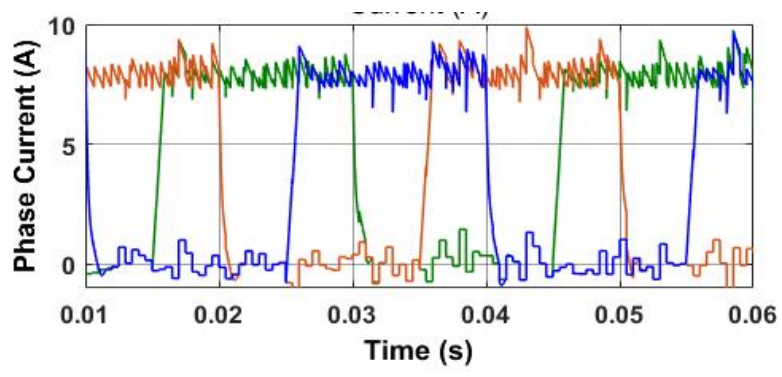

(b)

Fig. 3. Phase current of CCC method (a) without error (b) with error

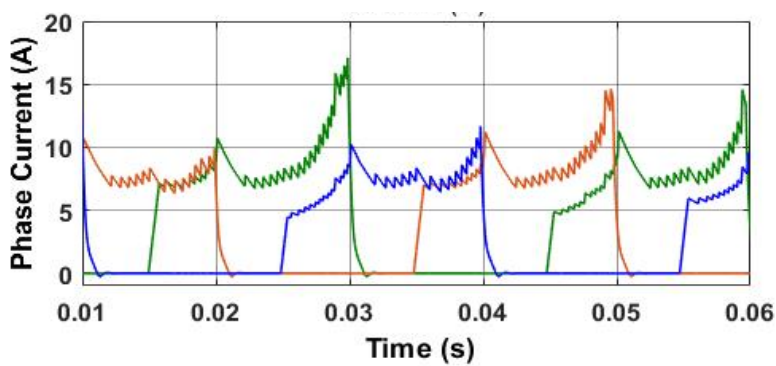

(a)

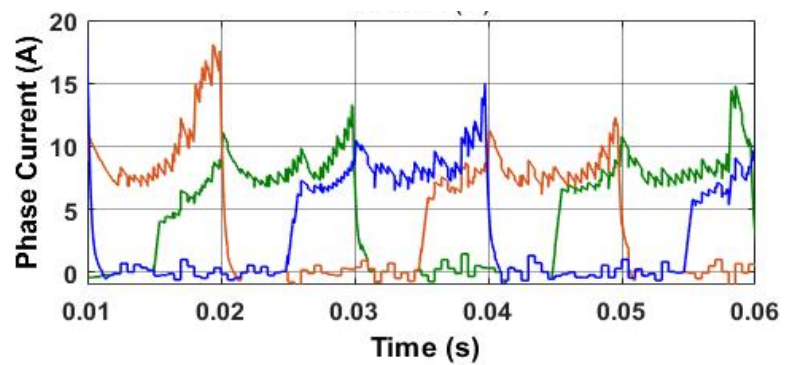

(b)

Fig. 4. Phase current of TSF-DITC method (a) without error (b) with error

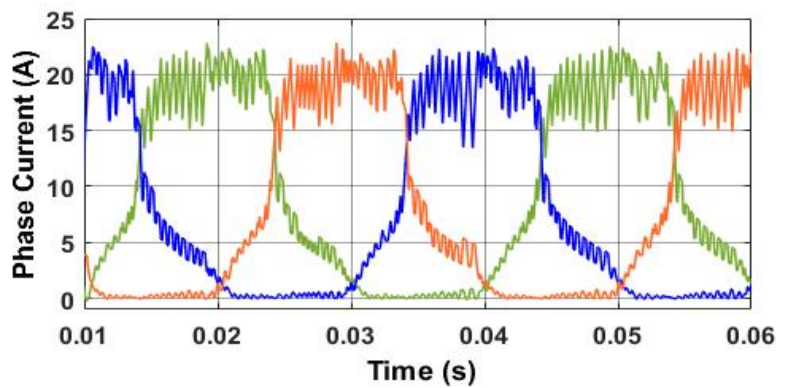

(a) 


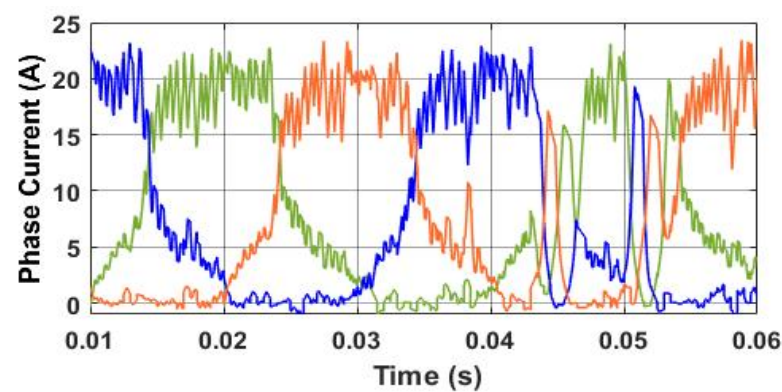

(b)

Fig. 5. Phase current of DTC method (a) without error (b) with error

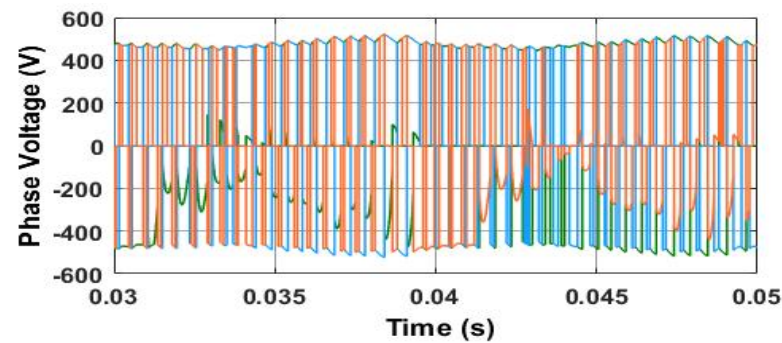

(a)

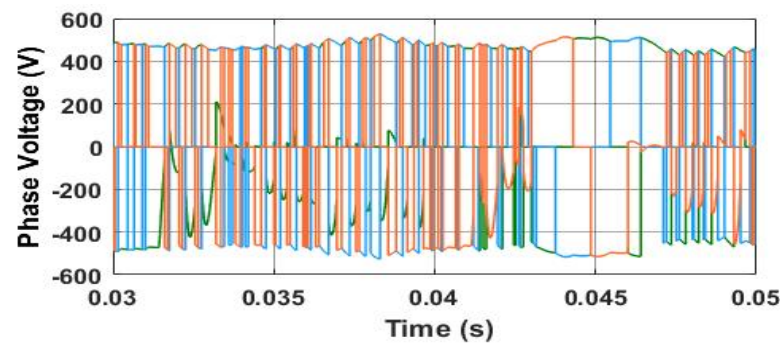

(b)

Fig. 6. Phase voltage of DTC method (a) without error (b) with erro

The comparison of the resultant torque with and without measurement uncertainties of the three control methods with the SRM running at low speed (hysteresis mode) and it high speed are presented in Figures 7-9. The effect of the error can be clearly observed because the performance of all the methods is affected at both speed levels. Nevertheless, a reliable control system should have a reasonable accuracy under certain level of uncertainties like the $10 \%$ deviation used in this study. From the result obtained, the CCC method shows better robustness to measurement error because the measured feedback is only used by the current hysteresis comparator. By observing the TSF-DITC and DTC results the deviation is high because the feedback signal is used by more than one component of the control methods.

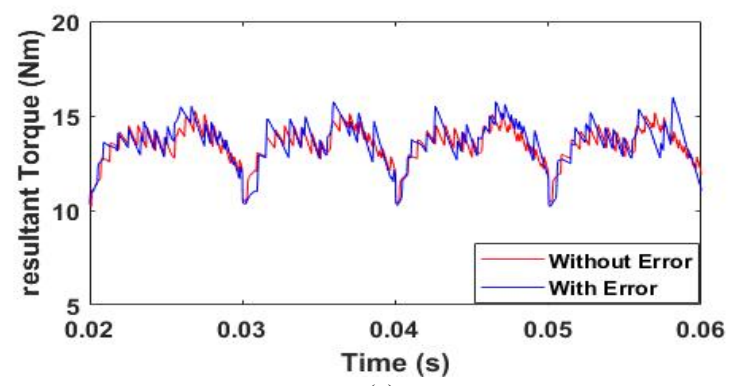

(a)

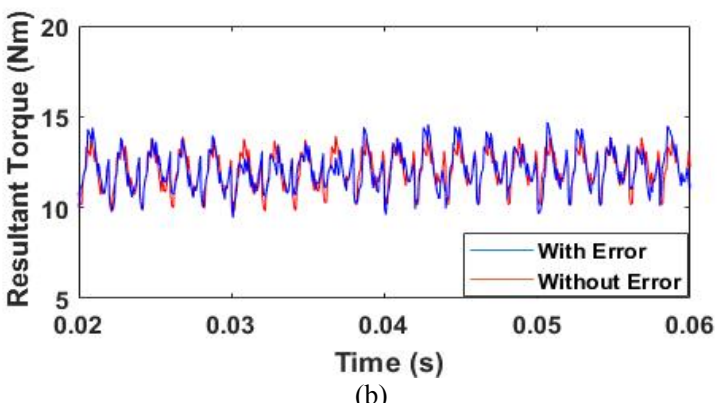

(b)

Fig. 7. Resultant torque of CCC method at (a) 100rpm (b) 500rpm

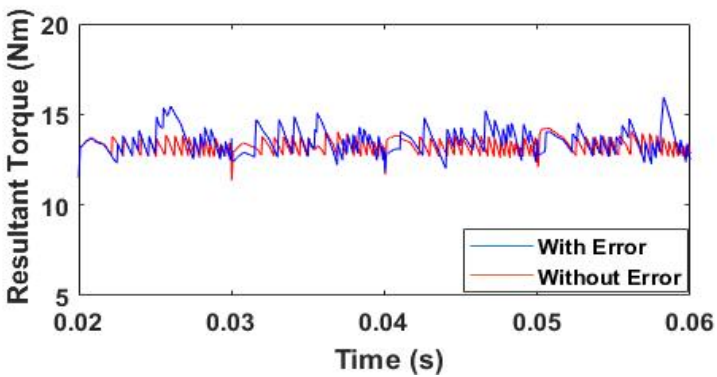

(a)

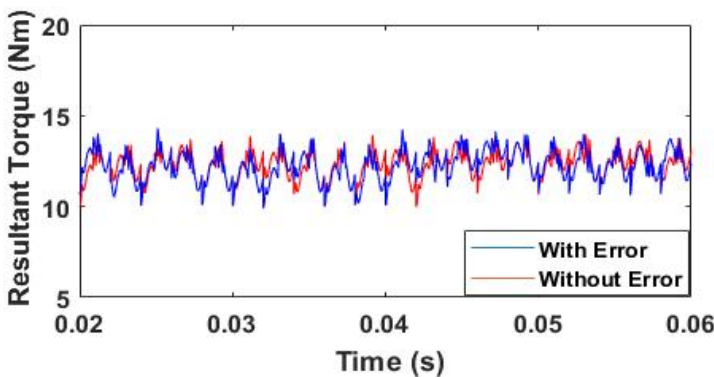

(b)

Fig. 8. Resultant torque of TSF-DITC method at (a)100rpm (b) 500rpm

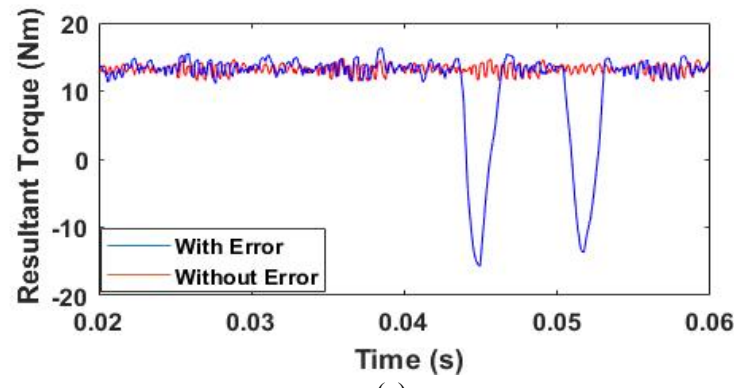

(a)

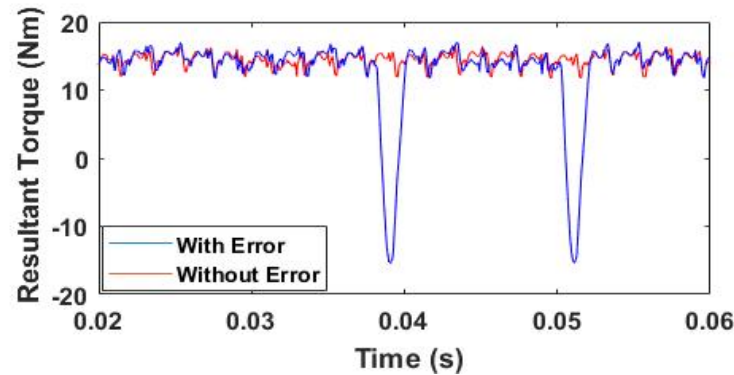

(b)

Fig. 9. Resultant torque of DTC method at (a)100rpm (b) 500rpm 
Table III summarised the comparison of the normalised peak to peak torque between the CCC method, the TSF-DITC and the DTC method with and without measurement error. Both the TSF-DITC and the DTC methods showed less peak to peak torque e compared to the $\mathrm{CCC}$ method at low and base speeds of the motor without the error signal injected into the measurement terminals. Nevertheless, the TSF-DITC shows less compare to the DTC at low speed. Adding the error signal to phase current measurement of the CCC method caused 4\% and $8 \%$ increase in peak to peak torque at $100 \mathrm{rpm}$ and $500 \mathrm{rpm}$ respectively. For the TSF-DITC method, the injected error caused $12 \%$ and $3 \%$ increase in peak to peak torque at $100 \mathrm{rpm}$ and 500rpm respectively. Lastly, results for the DTC method showed $257 \%$ and $216 \%$ increase in peak to peak torque at100rpm and 500rpm respectively, which is very large compared to the other two methods. This is because the DTC algorithm depends on both phase-current and phase-voltage measurements and with the error signal added to each, the flux and torque estimations produced erroneous values, hence, the zone selector can select a wrong switching sequence which can cause torque spikes as depicted in Fig. 9.

In summary, the $\mathrm{CCC}$ method shows the highest robustness to measurement error in the set of results depicted. However, the TSF-DITC method achieved superior torque characteristics while maintaining high robustness and reliability. Comparing these three methods, it is clear that increasing the functionality (complexity) of the control method, to improve its torque characteristics, in the case of DTC and TSF-DITC can increases the dependency of the method on the feedback signal hence, reducing its accuracy which can compromise its reliability.

TABLE III. NORMALISED PEAK TO PEAK TORQUE (\%)

\begin{tabular}{|c|c|c|c|}
\hline Methods & Speed & Without Error & With Error \\
\hline \multirow{2}{*}{ CCC } & $\mathbf{1 0 0} \mathbf{~ r p m}$ & $\mathbf{0 . 3 8}$ & $\mathbf{0 . 4 2}$ \\
\cline { 2 - 4 } & $\mathbf{5 0 0} \mathrm{rpm}$ & $\mathbf{0 . 3 5}$ & $\mathbf{0 . 4 3}$ \\
\hline \multirow{2}{*}{ TSF-DITC } & $\mathbf{1 0 0} \mathrm{rpm}$ & $\mathbf{0 . 2 1}$ & $\mathbf{0 . 3 3}$ \\
\cline { 2 - 4 } & $\mathbf{5 0 0} \mathrm{rpm}$ & $\mathbf{0 . 3 3}$ & $\mathbf{0 . 3 6}$ \\
\hline \multirow{2}{*}{ DTC } & $\mathbf{1 0 0} \mathrm{rpm}$ & $\mathbf{0 . 2 6}$ & $\mathbf{2 . 8 3}$ \\
\cline { 2 - 4 } & $\mathbf{5 0 0} \mathrm{rpm}$ & $\mathbf{0 . 3 3}$ & $\mathbf{2 . 4 9}$ \\
\hline
\end{tabular}

\section{CONCLUSION}

In this study, an analysis of the relationship between system structural complexity and reliability of SRM control is presented based on information flow complexity within the control technique. The results obtained showed that the CCC method shows the highest robustness to measurement error followed by the TSF-DITC then the DTC. The analysis depicted that $\mathrm{CCC}$ can provide high robustness to measurement errors, but it has poor torque ripple reduction capability compared to torque control methods. On the other hand, torque control methods such as TSF-DITC and DTC can provide a superior torque ripple reduction. However, the DTC has significantly less robustness to measurement noise and errors compared to the other two because its higher structural complexity increased the dependency of its accuracy to the accuracy of the feedback signal.

\section{REFERENCES}

[1] S. Ullah, S. P. McDonald, R. Martin, M. Benarous and G. J. Atkinson, "A Permanent Magnet Assist, Segmented Rotor, Switched Reluctance Drive for Fault Tolerant Aerospace Applications," in IEEE Transactions on Industry Applications, vol. 55, no. 1, pp. 298-305, Jan.-Feb. 2019.

[2] W. Lee, S. Li, D. Han, B. Sarlioglu, T. A. Minav and M. Pietola, "A Review of Integrated Motor Drive and Wide-Bandgap Power Electronics for High-Performance Electro-Hydrostatic Actuators," in IEEE Transactions on Transportation Electrification, vol. 4, no. 3, pp. 684-693, Sept. 2018

[3] J. Borg Bartolo, M. Degano, J. Espina and C. Gerada, "Design and Initial Testing of a High-Speed 45-kW Switched Reluctance Drive for Aerospace Application," in IEEE Transactions on Industrial Electronics, vol. 64, no. 2, pp. 988-997, Feb. 2017.

[4] S. P. McDonald, G. J. Atkinson, R. Martin and S. Ullah, "Magnetically biased inductor for an aerospace switched reluctance drive," 2015 IEEE International Electric Machines \& Drives Conference (IEMDC), Coeur d'Alene, ID, 2015, pp. 1272-1278.

[5] L. Castellini, S. Lucidi and M. Villani, "Design optimization of switched reluctance motor for aerospace application," 2015 IEEE International Electric Machines \& Drives Conference (IEMDC), Coeur d'Alene, ID, 2015, pp. 1678-1682.

[6] A. Xu, W. Zhang and P. Ren, "Comparison of torque ripple reduction for switched reluctance motor based on DTC and DITC," 2018 13th IEEE Conference on Industrial Electronics and Applications (ICIEA), Wuhan, 2018, pp. 1727-1732.

[7] Q. Sun, J. Wu, C. Gan, Y. Hu and J. Si, "OCTSF for torque ripple minimisation in SRMs," in IET Power Electronics, vol. 9, no. 14, pp. 2741-2750, 16112016.

[8] S. Pratapgiri, "Comparative analysis of Hysteresis Current Control and Direct Instantaneous Torque Control of Switched Reluctance Motor," 2016 International Conference on Electrical, Electronics, and Optimization Techniques (ICEEOT), Chennai, 2016, pp. 2856-2860.

[9] N. Sharygina, J. C. Browne, \& R. P. Kurshan,(2011) "A formal objectoriented analysis for software reliability: design for verification", pp: 115 .

[10] A. Yadav and R. A. Khan,(2010) "Bridging the gap between design constructs and reliability factors", CSI Communication, Vol. 33, No. 12, March 2010, pp: 29-32, ISSN 0970-647X.

[11] K. G. Popstojanova \& K. S. Trivedi,(2000) "Failure correlation in software reliability models", IEEE Transactions on Reliability, Vol. 49, NO. 1, pp: $37-48$.

[12] M. R. Lyu, (1994) "Software reliability: to use or not to use?", 5th International Symposium on Software Reliability Engineering, Proceedings, pp: $66-73$.

[13] A. D. Cheok and N. Ertugrul, "High robustness and reliability of fuzzy logic based position estimation for sensorless switched reluctance motor drives," in IEEE Transactions on Power Electronics, vol. 15, no. 2, pp. 319-334, March 2000.

[14] Henry S, Kafura D. Software structure metrics based on information flow. IEEE Trans. Software Eng., 1981, 7(5): 510-518.

[15] Y. Shi and S. Xu, "A new method for measurement and reduction of software complexity," in Tsinghua Science and Technology, vol. 12, no. S1, pp. 212-216, July 2007.

[16] Henry S, Kafura D. Information flow metrics for the evaluation of operating systems' structure. Ames: Iowa State Univ., 1979: 68-80.

[17] Fenton N, Pfleeger S. Software Metrics: A Rigorous and Practical Approach. London: Thomson Computer, 2002:305-350.

[18] Y. Chu and S. Xu, "Exploration of complexity in software reliability," in Tsinghua Science and Technology, vol. 12, no. S1, pp. 266-269, July 2007.

[19] Belady L A, Evangelisti C J. System partitioning and measuring. IBM Res. Rep. RC7560, 1979: 120-131 